Crystallography. The recipients to date are as follows:

$\begin{array}{cll}\text { Year } & \text { Place } & \text { Recipients } \\ 1987 & \begin{array}{l}\text { Perth, } \\ \text { Australia }\end{array} & \begin{array}{l}\text { Professor J. M. } \\ \text { Cowley and } \\ \text { Dr A. F. Moodie }\end{array} \\ 1990 & \begin{array}{l}\text { Bordeaux, } \\ \text { France }\end{array} & \begin{array}{l}\text { Professor B. K. } \\ \text { Vainshtein }\end{array} \\ 1993 \begin{array}{l}\text { Beijing, } \\ \text { China }\end{array} & \text { Professor N. Kato }\end{array}$

The fourth Prize, for which nominations are now being invited, will be presented at the XVII Congress in Seattle, Washington, USA, in August 1996.

Scientists who have made contributions of exceptional distinction to the science of crystallography are eligible for the Ewald Prize, irrespective of nationality, age or experience. The Selection Committee will give careful attention to the nominations of outstanding scientists who have not yet won a major prize. Either an exceptionally distinguished scientific career or a major scientific accomplishment may be recognized. Current members of the Selection Committee and the President of the IUCr are not eligible. No restrictions are placed on the time or the means of publication of the nominee's contributions. The Prize may be shared by more than one contributor, but not more than three, to the same scientific achievement.

Nominations for the Ewald Prize should be submitted in writing, preferably using the Ewald Prize Nomination Form and accompanied by supporting documentation, to the Executive Secretary of the International Union of Crystallography, 2 Abbey Square, Chester $\mathrm{CH}_{1} 2 \mathrm{HU}$, England, from whom copies of the Nomination Form and the names of the Selection Committee may be obtained. The closing date for nominations is 31 August 1995.

P. Coppens

A. I. HoRDvik

President General Secretary

\section{Notes and News}

J. Appl. Cryst. (1995). 28, 67

\section{ECM16: Oxford Cryosystems Award}

During ECM16 in Lund, Sweden, 6-11 August 1995, Oxford Cryosystems will be awarding a prize of $£ 250$ for the best poster describing low-temperature crystallography. The award will be made either for a description of low-temperature equipment or for any research in which low temperatures are a major feature. Judges will be selected by the Organizing Committee of ECM16 and the prize will be presented during the conference banquet.

\section{New Commercial Products}

Announcements of new commercial products are pub lished by the Journal of Applied Crystallography free of charge. The descriptions, up to $\mathbf{3 0 0}$ words or the equivalent if a figure is included, should give the price and the manufacturer's full address. Full or partial inclusion is subject to the Editor's approval and to the space available. All correspondence should be sent to the Editor, Dr A. M. Glazer, Editor Journal of Applied Crystallography, Clarendon Laboratory, University of Oxford, Parks Road, Oxford OX1 3PU. England.

The International Union of Crystallography can as sume no responsibility for the accuracy of the claims made. A copy of the version sent to the printer is sent to the company concerned.

\section{J. Appl. Cryst. (1995). 28, 67}

Zinc Germanium Phosphide for IR Generation between 2.6 and $11 \mu \mathrm{m}$

INRAD announces that it has developed zinc germanium phosphide (ZPG) having improved transmission characteristics in the near-IR, making it an excellent choice for generating tuneable IR with a near-IR pump. This nonlinear crystal was first introduced by INRAD at the CLEO 93 trade show and was made available to customers on a limited basis.

ZGP has a nonlinear coefficient $\left(75 \mathrm{pm} \mathrm{V}^{-1}\right)$ more than twice that of silver gallium selenide $\left(\mathrm{AgGaSe}_{2}\right)$ and has a much higher thermal conductivity $\left(0.18 \mathrm{~W} \mathrm{~cm} \mathrm{~K}^{-1}\right)$, which is important for generating high average power. It is transmissive from 0.67 to $13 \mu \mathrm{m}$, a wavelength region that is vitally important as the 'fingerprint' region for molecular species. ZPG has been demonstrated as the frequency converter in an OPO configuration, which opens the door to applications in remote sensing and countermeasures.

INRAD manufactures crystals, laser components, optical coatings, laser systems and instruments for scientific, defense, aerospace and industrial markets.

INRAD, Legrand Avenue, Northvale, NJ 07647, USA.

\section{J. Appl. Cryst. (1995). 28, 67}

\section{$-80^{\circ} \mathrm{C}$ Immersion Cooling}

The new CFC-free mechanically refrigerated LFC80 Flexi-Cool coil-style probe provides up to $550 \mathrm{~W}$ of heat removal capacity while maintaining an alcohol bath temperature at $-80^{\circ} \mathrm{C}$. A microprocessor temperature controller permits the user to set and maintain bath temperature to $0.1^{\circ} \mathrm{C}$ between 0 and $-80^{\circ} \mathrm{C}$. The stainless steel coil probe configuration ensures maximum temperature uniformity within the bath and makes the coil an ideal replacement for $\mathrm{CO}_{2}$ or liquid $\mathrm{ni}$ trogen for cooling chemical reaction vessels, cold baths or vapour trapping.

FTS Systems, Inc., PO Box 158, Stone Ridge, NY 12484, USA.

\section{J. Appl. Cryst. (1995). 28, 67}

\section{Ultrahigh Vacuum Chambers - a New Service from ITL}

Instrument Technology Limited has identified a need for specialized highvacuum and UHV chambers and has expanded its facilities by installing a new 2000 square feet Chamber Division.

Casualties in the vacuum industry resulting from the recession mean that there are fewer companies with the specialized facilities and expertise to manufacture high-specification UHV chambers. ITL has assembled an experienced team with the capability to answer the demanding requirements of customers in science-based industries and research and development.

High-vacuum and UHV chambers up to $2 \mathrm{~m}^{3}$ are typically manufactured from $304 \mathrm{~L}$ or $316 \mathrm{~L}$ stainless steel to customers' specifications and drawings. A design service is offered whereby customers can discuss their applications with ITL's design engineers who will then submit drawings for approval before manufacture.

Chambers are supplied fully leak tested and chemically cleaned to UHV standards. Non-magnetic mu-metal liners can be supplied where required. Complete vacuum systems with all necessary fittings and accessories from ITL's extensive range can be assembled. ITL's latest vacuum components catalogue includes a section introducing the facilities of the new Vacuum Chamber Division.

Instrument Technology Limited, Castleham Road, St Leonards-on-Sea, East Sussex TN38 9NS, England.

\section{J. Appl. Cryst. (1995). 28, 67-68}

\section{New ITL Catalogue with more than 2000 Vacuum Components}

The new 1994/5 Vacuum Components Catalogue from Instrument Technology Limited provides vacuum process engineers and scientists with a 105-page guide to ITL's comprehensive range of $\mathrm{KF}$, ISO and CF components.

In addition to the essential range of basic construction fittings in a choice of high-quality stainless steels, the 